Reprod. Nutr. Dévelop., 1987, 27 (1 B), 277-278.

\title{
Interaction entre espèce animale et nature de l'aliment concentré sur la digestibilité de la ration chez le ruminant
}

Brigitte MICHALET-DOREAU, Y. GEAY $\left(^{*}\right)$, M. DOREAU $\left(^{* *}\right)$, C. PONCET $\left.1^{* *}\right)$

Laboratoire des Aliments,

(*) Laboratoire de la Production de Viande,

(**) Laboratoire de la Lactation,

(**) Laboratoire de la Digestion,

I.N.R.A., Theix, 63122 Ceyrat, France.

Summary. The digestibility of diets based on high cell-wall concentrate $(60 \%$ bran or beet pulp) and hay ( $40 \%$ ) was studied at two intake levels (maintenance and ad libitum) in sheep, steers and cows. Between-species differences in digestibility were especially evident with the bran diets. Moreover, when the level of intake increased, digestibility decreased more in sheep than in cows.

La mesure de la digestibilité des aliments destinés aux ruminants est habituellement réalisée sur des ovins. Pour extrapoler les résultats aux bovins, il est cependant nécessaire de connaître les éventuelles différences de digestibilité entre ces espèces. De telles études ont été récemment menées par Uden et Van Soest (1984) et Prigge et al. (1984) sur des rations à base de fourrage. Cet essai a eu comme objectif de comparer chez des ovins et des bovins les digestibilités des rations contenant des sous-produits riches en parois : le son de blé ou la pulpe de betterave déshydratée.

Matériel et méthodes. Le son $[10,6 \%$ de cellulose brute (CB) et $52,0 \%$ de parois (NDF) dans la matière sèche] et la pulpe $[18,7 \% \mathrm{CB}$ et $47,8 \% \mathrm{NDF}]$ ont chacun été distribués en association avec un foin de luzerne-dactyle dans des proportions respectives de $59,5 \pm 2,0$ et $40,5 \pm 2,0$ et à deux niveaux d'alimentation : entretien et ad libitum. Trois types de ruminants ont reçu ces rations : 6 béliers adultes castrés (M) $(53 \pm 5 \mathrm{~kg}) ; 6$ bouvillons Salers (B) âgés de 12 à 16 mois (386 $\pm 29 \mathrm{~kg}) ; 6$ vaches Pie Noire taries (VT), non gestantes $(659 \pm 47 \mathrm{~kg})$ pour les mesures à l'entretien et 6 vaches Pie Noire en lactation (VL) produisant $15,9 \mathrm{~kg}$ de lait et pesant $585 \pm 102 \mathrm{~kg}$ pour les études ad libitum. Pour chaque type d'animaux, les besoins d'entretien ont été estimés respectivement à $0,029-0,049$ et 0,040 UFL/ $\mathrm{kg} \mathrm{P}^{0,75}$ (INRA, 1978). La digestibilité a été mesurée au cours de périodes de 6 jours après 2 ou 3 semaines d'adaptation, et les résultats comparés par espèce lanalyse de variance de type factoriel $2 \times 2$, régime $x$ niveau).

Résultats et discussion. La digestibilité de la matière organique (dMO) est du même ordre de grandeur chez les bouvillons et les vaches laitières, et plus élevée que chez les ovins (tabl. 1), mais la différence entre les deux espèces varie fortement selon la nature du régime et le niveau d'alimentation.

A l'entretien, elle est importante pour la ration contenant du son $(+6,1)$ mais elle disparaît pour la ration à base de pulpe. Ces différences de digestibilité entre espèces observées avec le régime son portent à croire à une meilleure utilisation digestive par les bovins de certains constituants pariétaux, et en particulier des hémicelluloses dont la teneur est élevée dans ce régime. 
La distribution à volonté entraîne une augmentation de l'ingestion quel que soit le régime ou l'espèce, sauf chez les moutons recevant la ration à base de son. L'augmentation du niveau d'ingestion entraîne une diminution significative de la dMO chez les vaches (- 3,0 avec les 2 types de régime) et chez les ovins $(-4,2$ avec le régime " pulpe "), mais plus importante chez ces derniers. En revanche, elle s'accompagne d'une augmentation de la dMO (en moyenne $+3,4$ ) chez les bouvillons sans qu'on puisse l'expliquer ni par des variations de pourcentage de concentré, ni par un développement important de leur tractus digestif.

TABL. 1. - Influence du niveau d'alimentation sur les quantités ingérées et la digestibilité des régimes "son" ou " pulpe" ", chez les moutons, les bouvillons et les vaches.

\begin{tabular}{|c|c|c|c|c|c|c|}
\hline Régime foin + sor & \multicolumn{2}{|c|}{$\begin{array}{c}\text { Moutons } \\
\text { Entretien } A d . \text { lib. }\end{array}$} & \multicolumn{2}{|c|}{$\begin{array}{c}\text { Bouvillons } \\
\text { Entretien } A d . \text { lib. }\end{array}$} & \multicolumn{2}{|c|}{$\begin{array}{c}\text { Vaches } \\
\text { Entretien } \boldsymbol{A d} . \text { lib. }\end{array}$} \\
\hline $\begin{array}{l}\text { g MS } / \mathrm{kg} \mathrm{P.75} \\
\text { g MOD } / \mathrm{kg} \mathrm{P.75} \\
\text { d MO } \\
\text { d CB }\end{array}$ & $\begin{array}{l}40,4 \\
22,8 \\
61,9 \\
43,7\end{array}$ & $\begin{array}{l}56,0 \\
31,4 \\
61,5 \\
45,7\end{array}$ & $\begin{array}{l}52,5 \\
32,8 \\
67,4 \\
49,5\end{array}$ & $\begin{array}{l}90,7 \\
59,4 \\
70,5 \\
56,9\end{array}$ & $\begin{array}{l}50,0 \\
31,9 \\
68,5 \\
52,8\end{array}$ & $\begin{array}{r}111,6 \\
67,8 \\
65,6 \\
50,7\end{array}$ \\
\hline \multicolumn{7}{|c|}{ Régime foin + pulpe } \\
\hline $\begin{array}{l}\text { g MS/kg P. } 75 \\
\text { g MOD } / \mathrm{kg} \mathrm{P.75} \\
\text { d MO } \\
\text { d CB }\end{array}$ & $\begin{array}{l}36,5 \\
24,8 \\
74,5 \\
65,8\end{array}$ & $\begin{array}{l}75,0 \\
48,1 \\
70,3 \\
59,4\end{array}$ & $\begin{array}{l}46,8 \\
31,1 \\
72,9 \\
64,9\end{array}$ & $\begin{array}{l}86,9 \\
59,6 \\
76,6 \\
72,0\end{array}$ & $\begin{array}{l}46,9 \\
32,4 \\
75,8 \\
69,7\end{array}$ & $\begin{array}{r}131,6 \\
87,6 \\
72,8 \\
64,5\end{array}$ \\
\hline
\end{tabular}

Pour les 3 espèces les effets du régime et du niveau alimentaire sont significatifs $(P<0,001)$ mais les interactions ne le sont pas.

La digestibilité plus élevée chez les bovins a souvent été attribuée à un allongement du temps de séjour des aliments dans le rumen (Carle et Dulphy, 1980), ce que confirment Poncet et al. (1987) dans le cadre de cette étude pour l'ensemble du tube digestif. Mais les différences de temps de séjour entre les espèces ne peuvent toutefois expliquer les interactions digestives espèce $\times$ régime.

Carle B., Dulphy J. P., 1980. Reprod. Nutr. Dévelop., 20, 1633-1639.

INRA, 1978. Alimentation des Ruminants, INRA Publ., route de St-Cyr, 78000 Versailles.

Poncet C., Gomez L., Michalet-Doreau B., Geay Y., 1987. Reprod. Nutr. Dévelop., 27, 219-220.

Prigge E. C., Baker M. J., Varga G. A., 1984. J. anim. Sci., 59, 237-245.

Uden P., Van Soest P. J., 1984. J. anim. Sci., 58, 213-221. 